\title{
Powder Metallurgical Fabrication and Microstructural Investigations of Aluminum/Steel Functionally Graded Material
}

\author{
Mahmoud M. Nemat-Alla ${ }^{1}$, Moataz H. Ata ${ }^{2}$, Mohamed R. Bayoumi ${ }^{3}$, Wael Khair-Eldeen ${ }^{4}$ \\ ${ }^{1}$ Mechanical Engineering Department, Assiut University, Assiut, Egypt; ${ }^{2}$ Faculty of Industrial Education, Sohag University, Sohag, \\ Egypt; ${ }^{3}$ Mechanical Engineering Department, Assiut University, Assiut, Egypt; ${ }^{4}$ Mechanical Engineering Department, Assiut Uni- \\ versity, Assiut, Egypt. \\ E-mail: nematala1@yahoo.com
}

Received October $8^{\text {th }}, 2011$; revised November $24^{\text {th }}, 2011$; accepted December $3^{\text {rd }}, 2011$.

\begin{abstract}
Aluminum/steel electric transition joints (ETJs) are used in aluminum reduction cell for the purpose of welding aluminum rod and steel bracket components. Solid state welding process used for joining aluminum and steel at the electric transition joints have the drawbacks of cracking and separation at the interface surfaces. Cracking and separation at the electric transition joints are caused by the stress singularities that developed due to the mismatch in thermal and mechanical properties of each material. To overcome the drawback of electric transition joints, aluminum/steel functionally graded may be used as electric transition joints or proposed. Therefore manufacturing and investigation of aluminum/steel functionally graded materials fabricated by powder metallurgy process were carried out through the current work. Different samples with different layers of aluminum/steel functionally graded materials were compacted using steel die and punch at the same compacted pressure and sintered temperature. After investigating the different samples of aluminum/steel functionally graded materials under different fabrication conditions, the suitable fabrication regime was determined with the aid of microscopic observations.
\end{abstract}

Keywords: Powder Metallurgy, Functionally Graded Materials, Aluminum/Steel Electric Transition Joint, Microstructural Investigations

\section{Introduction}

Electrolytic reduction cells of aluminum require high current density that passed through the electrical connection between an aluminum rod and a steel bracket. Bolted connection between the aluminum rod and the steel bracket exhibit high electrical resistance, in addition to deterioration over the time due to oxide buildup, corrosion, and arcing. Therefore, welding processes may be the suitable way for joining the aluminum and steel materials. Unfortunately, all the various permutations of aluminum and steel are nonwelded by traditional fusion welding processes. The difficulties in the welding of aluminum with steel by fusion welding processes have been a great challenge for engineering, because they result from hard and brittle intermetallic phases that are formed between aluminum and steel at elevated temperatures $\left(\mathrm{Fe}_{3} \mathrm{Al}, \mathrm{FeAl}, \mathrm{FeAl}_{2}\right.$, $\mathrm{Fe}_{2} \mathrm{Al}_{5}, \mathrm{FeAl}_{3}$ ) [1]. Solid state welding process, such as explosion welding, cold roll bonding, and friction welding, provide a means for making a strong, ductile metallurgical bond between these various metal combinations [2-6]. However, none of these technologies are suitable for traditional equipment fabrications. The concept of an electrical transition joint (ETJ) was introduced as a practical solution for joining the aluminum and steel materials in the electrolytic reduction cells of aluminum. ETJ's are small bi-metallic inserts between aluminum rod and steel bracket. The upper surface of the bi-metallic insert (aluminum) is welded by the aluminum rod while the lower surface (steel) is welded by the steel bracket. ETJ's are manufactured using one of the solid state welding processes, such as explosion welding, cold roll bonding, and friction welding. In the cold roll-bonding process, aluminum and steel plates are passed through a rolling mill with sufficient pressure and reduction to break-up surface oxides on the mating surfaces and create bonding between the dissimilar metals [7]. The main drawback of the bimetallic materials is cracks initiation and propagations or 
separation at the interface surfaces under thermal and mechanical loads. This may be attributed to the stress singularities at the interface surfaces due to the mismatch in thermal and mechanical properties of each material component.

Recently, functionally graded material (FGM) concept is proposed to overcome the above drawbacks [8-12]. FGM is a mixture of two different distinct materials fabricated in such a way that the volume fractions of the constituents are varied gradually in a predetermined composition profile. The profile of the composition is starting with $100 \%$ of one material at a surface of the plate and varied gradually with intermediate composition through the thickness of the plate, where the microstructure and properties are smoothly varied, ending with $100 \%$ of the other material at the other surface. It is worthy note that the gradual variation in composition in FGM does not have the internal boundaries found in multilayer materials, and hence it exhibit better resistance to thermal and mechanical loads [13]. Therefore, FGM overcomes the drawback of bi-metallic plates, such as ETJ's, due to gradual variation of thermal and mechanical properties. In the current investigations FGM concept was adopted in order to overcome the drawbacks of using aluminum/ steel ETJ's. The aluminum/steel ETJ will be replaced by aluminum/steel functionally graded layers plate, where composition are smoothly varied through the thickness of the plate from $100 \%$ aluminum at one surface to $100 \%$ steel at the other surface.

Various techniques have been employed to fabricate FGM such as chemical and physical vapor deposition (CVD/PVD), plasma spraying, electroplating and combustion synthesis, self propagating high-temperature synthesis (SHS), centrifugal casting, controlled mold filling and powder metallurgical processing [14]. Powder metallurgical processing is one of most viable routes for manufacturing of FGM [15]. Production of FGM by powder metallurgical (PM) processing involves rapid solidification that offers unique advantages that are important to the ductility of the material. For example, segregation in the powdered material can be minimized, very fine grains can be produced and solid solubility of alloying elements can be increased [15,16]. PM major advantages are; cost effectiveness in producing certain parts as compared to other manufacturing processes, high production rates, production of complex shapes, bimetallic and laminated special purpose parts can be made from mould layers and different metallic powders, certain types of parts can be made only by PM by mixing different metals, non-metals, metals and ceramics etc., to achieve the desired properties of the component such as, production of cermets (ceramic + metals), mechanically alloyed super alloys and copper welding electrodes with dispersed alumina $\left(\mathrm{Al}_{2} \mathrm{O}_{3}\right)$ [17]. Because all of these advantages, PM processes are ideally suited for fabricating aluminum/steel Functionally Graded materials that can be effectively used as electric transition joints which is the purpose of the current investigations.

\section{Eexperimental Work and Investigations}

\subsection{Powder Characteristics}

The raw powders used in the current investigations were aluminum powder with $95.07 \%$ purity and steel powder with $99.01 \%$ purity. Scanning electron microscopy of aluminum and steel raw powders used in the PM production operation, as received from the supplier, at magnifycation of $\times 100$ are shown in Figure 1. The aluminum particles have irregularly shaped with rough surface projecttions while the steel particles have relatively spherical shaped with rough surface projections. The apparent density of Aluminum powder and Steel Powder were found to be $1176.5 \mathrm{Kg} / \mathrm{m}^{3}$ and $3658.5 \mathrm{Kg} / \mathrm{m}^{3}$ respectively. The particle size distribution of aluminum and steel powders were performed and the obtained results are listed in Table 1. It can be noticed that the aluminum powder and the steel powder are nearly of the same size distribution which will give homogenous distribution of the reinforcement through the matrix. Also, the chemical compositions of the two adopted powders are listed in Table 2.

\subsection{FGM Processing by Powder Metallurgy}

\subsubsection{Mixing and Blending Operation}

Six cylindrical specimens of aluminum/steel FGM were produced with different number of layers (2, 3, 6, 9, 15 and 21 layers). The compositions of the specimens were gradually varied from $100 \%$ of aluminum powder in one side to $100 \%$ of steel powder in other side with intermediate graded composition between the two sides. The six

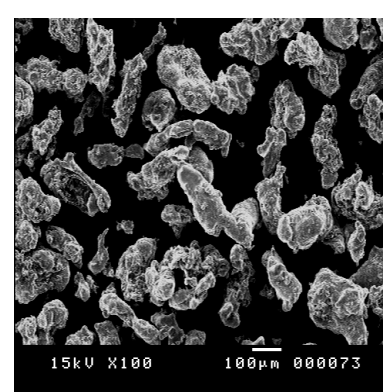

(a)

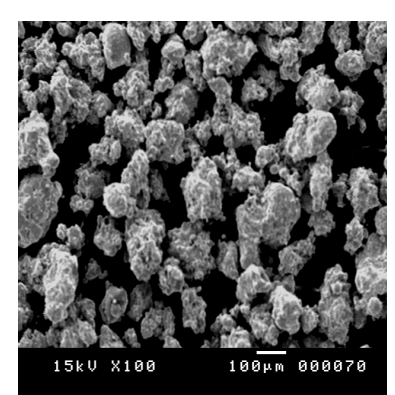

(b)
Figure 1. Scanning electron microscopy of aluminum and steel powders at magnification of $\times \mathbf{1 0 0}$. (a) Aluminum powder; (b) Steel powder. 
cylindrical specimens of aluminum/steel FGM were used to investigate the effect of the graded compositions and the number of layers on the microstructure. The weight percent and volume fraction variations through each layer in the specimens are listed in Table 3. The composition of each layer was calculated and the mixture was blended in dental amalgamator (YDM China) blender for 5 minutes to reach a homogenous distribution of the reinforcement in the mixture.

Table 1. Particle size distribution of aluminum and steel powders.

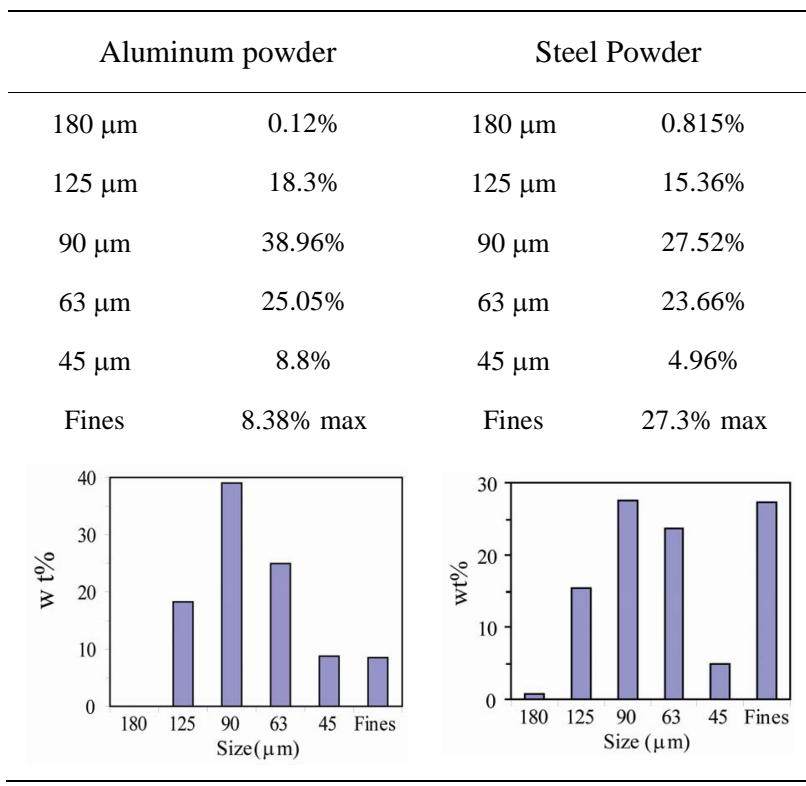

Table 2. Chemical composition of aluminum and steel powders.

\begin{tabular}{cccc}
\hline $\begin{array}{c}\text { Composition analysis of pure } \\
\text { aluminum in weight percent } \\
(\text { wt } \%)\end{array}$ & $\begin{array}{c}\text { Composition analysis of pure } \\
\text { steel in weight percent } \\
\text { (wt\%) }\end{array}$ \\
\hline $\mathrm{Al}$ & $95.07 \%$ & $\mathrm{Fe}$ & $99.01 \%$ \\
$\mathrm{Si}$ & $3 \%$ & $\mathrm{Ni}$ & $0.51 \%$ \\
$\mathrm{~S}$ & $0 \%$ & $\mathrm{Cu}$ & $0.19 \%$ \\
$\mathrm{Cl}$ & $0.15 \%$ & $\mathrm{Al}$ & $0.14 \%$ \\
$\mathrm{Fe}$ & $0.7 \%$ & $\mathrm{~S}$ & $0.07 \%$ \\
$\mathrm{Ni}$ & $0.11 \%$ & $\mathrm{Cl}$ & $0.08 \%$ \\
$\mathrm{Cu}$ & $0.57 \%$ & & \\
$\mathrm{Zn}$ & $0.4 \%$ & & \\
\hline
\end{tabular}

Table 3. Aluminum and steel weight and volume percentage in each layer.

\begin{tabular}{|c|c|c|c|c|c|}
\hline \multicolumn{2}{|c|}{ Specimen and layers } & \multicolumn{2}{|c|}{ Aluminum powder } & \multicolumn{2}{|c|}{ Steel powder } \\
\hline Codes & Layer No. & wt\% & vol\% & $w t \%$ & vol\% \\
\hline \multirow{2}{*}{$S_{1}$} & 1 & 0 & 0 & 100 & 100 \\
\hline & 2 & 100 & 100 & 0 & 0 \\
\hline \multirow{3}{*}{$\mathrm{S}_{2}$} & 1 & 0 & 0 & 100 & 100 \\
\hline & 2 & 50.01 & 74.43 & 50.06 & 25.56 \\
\hline & 3 & 100 & 100 & 0 & 0 \\
\hline \multirow{6}{*}{$\mathrm{S}_{3}$} & 1 & 0 & 0 & 100 & 100 \\
\hline & 2 & 20.01 & 42.16 & 79.99 & 57.83 \\
\hline & 3 & 39.98 & 66.02 & 59.99 & 33.98 \\
\hline & 4 & 59.99 & 81.38 & 40 & 18.61 \\
\hline & 5 & 79.98 & 92.1 & 19.99 & 7.89 \\
\hline & 6 & 100 & 100 & 0 & 0 \\
\hline \multirow{9}{*}{$\mathrm{S}_{4}$} & 1 & 0 & 0 & 100 & 100 \\
\hline & 2 & 12.51 & 29.41 & 87.52 & 70.59 \\
\hline & 3 & 24.99 & 49.26 & 75.01 & 50.73 \\
\hline & 4 & 37.49 & 63.62 & 62.5 & 36.38 \\
\hline & 5 & 49.99 & 74.45 & 50.01 & 25.55 \\
\hline & 6 & 62.49 & 82.93 & 37.51 & 17.07 \\
\hline & 7 & 75 & 89.74 & 24.99 & 10.26 \\
\hline & 8 & 87.51 & 95.33 & 12.51 & 4.67 \\
\hline & 9 & 100 & 100 & 0 & 0 \\
\hline \multirow{15}{*}{$\mathrm{S}_{5}$} & 1 & 0 & 0 & 100 & 100 \\
\hline & 2 & 7.15 & 18.34 & 92.81 & 81.65 \\
\hline & 3 & 14.31 & 32.73 & 85.69 & 67.27 \\
\hline & 4 & 21.41 & 44.26 & 78.61 & 55.74 \\
\hline & 5 & 28.49 & 53.74 & 71.49 & 46.26 \\
\hline & 6 & 35.69 & 61.79 & 64.31 & 38.2 \\
\hline & 7 & 42.77 & 68.43 & 57.49 & 31.56 \\
\hline & 8 & 49.98 & 74.43 & 50.03 & 25.57 \\
\hline & 9 & 57.39 & 79.61 & 42.85 & 20.39 \\
\hline & 10 & 64.17 & 83.95 & 35.77 & 16.45 \\
\hline & 11 & 71.39 & 87.96 & 28.49 & 12.04 \\
\hline & 12 & 78.55 & 91.44 & 21.43 & 8.56 \\
\hline & 13 & 85.68 & 94.58 & 14.3 & 5.42 \\
\hline & 14 & 92.76 & 97.42 & 7.15 & 2.58 \\
\hline & 15 & 100 & 100 & 0 & 0 \\
\hline \multirow{21}{*}{$S_{6}$} & 1 & 0 & 0 & 100 & 100 \\
\hline & 2 & 5.01 & 13.3 & 94.99 & 86.69 \\
\hline & 3 & 10.01 & 24.49 & 90 & 75.5 \\
\hline & 4 & 14.98 & 33.94 & 84.99 & 66.05 \\
\hline & 5 & 20.01 & 42.17 & 80 & 57.82 \\
\hline & 6 & 24.99 & 49.26 & 75.01 & 50.73 \\
\hline & 7 & 29.97 & 55.51 & 70.02 & 44.48 \\
\hline & 8 & 34.98 & 61.06 & 65 & 38.93 \\
\hline & 9 & 40.01 & 66.01 & 60.04 & 33.98 \\
\hline & 10 & 45.02 & 70.46 & 55.02 & 29.54 \\
\hline & 11 & 49.99 & 74.45 & 50.01 & 25.55 \\
\hline & 12 & 54.99 & 78.08 & 44.99 & 21.92 \\
\hline & 13 & 59.98 & 8138 & 40 & 18.62 \\
\hline & 14 & 65.01 & 84.41 & 35.01 & 15.59 \\
\hline & 15 & 69.99 & 87.18 & 30.01 & 12.82 \\
\hline & 16 & 74.95 & 89.73 & 24.99 & 10.27 \\
\hline & 17 & 80.02 & 92.11 & 19.97 & 7.88 \\
\hline & 18 & 84.94 & 94.29 & 14.97 & 5.7 \\
\hline & 19 & 89.95 & 96.33 & 9.98 & 3.67 \\
\hline & 20 & 94.98 & 98.21 & 5.03 & 1.78 \\
\hline & 21 & 100 & 100 & 0 & 0 \\
\hline
\end{tabular}




\subsubsection{Compaction}

The die, upper and lower punches were lubricated using Zinc stearate fine powder, to prevent adhesion of powder with die surface and decrease the coefficient of friction between die bore surface and powder, then the lower punch was assembled with the die cavity. Two different techniques of powder compaction were used in the current study. First one is, after mixing and blending process for the composition of each layer it was pre-compacted under low pressure before stacking the next layer. After that all layers compacted at 990.694 MPa (correspond to machine load of 35 ton) at a press of 500 ton capacity produced by (werkstoffprufmaschinen WPM Germany). Three layers $\left(S_{2}\right)$ and 6-layers $\left(S_{3}\right)$ specimens were fabricated using this technique. After compaction it was found that separation occurred between the green specimen layers, this may be attributed to the separating surface formed through the layer interface as shown in Figures 2(a) and (b). To avoid separating surface occurred when using the first technique, the mixed powders were sequentially stacked in the die, layer by layer, with a stepwise compositional distributions. Also, the specimen was compacted at 990.7 MPa without pre-compaction pressure. This was the second technique. The compositional of the specimen changes from $100 \%$ steel to $100 \%$ aluminum through the different layers. Using the second technique it was found that no separation occurred between layers in green specimens.

Also, it seems that good mechanical interlock between the different layers of the specimen is achieved. New six specimens $\left(S_{1}, S_{2}, S_{3}, S_{4}, S_{5}\right.$ and $\left.S_{6}\right)$ were compacted successfully using the second technique.

\subsubsection{Sintering Process}

Green compact specimen cannot be used because it has many drawbacks. In order to overcome such drawbacks sintering process is needed. The sintering temperature for powder varies in the range from 0.7 to 0.9 of the melting point. Due to variation of the melting temperature of the basic components of the specimen, aluminum and steel, two sets of sintering temperature were adopted, $800^{\circ} \mathrm{C}$ and $600^{\circ} \mathrm{C}$. The adopted sets of sintering temperature were above and below the melting point of aluminum. Usually, sintering time depends upon the specimen dimensions and type of the metal. However for Alnico magnets, it is 2 h. [18]. After sintering process it was found that failure occurred in specimens that sintered at $800^{\circ} \mathrm{C}$. This failure can be attributed to a new compound that has formed between aluminum and steel at elevated temperature. Therefore, the sintering temperature should be less than the melting point of both powders constitutes.
All six specimens with different number of layers and compositions, as listed in Table 3, that sintered at $600^{\circ} \mathrm{C}$ for $2 \mathrm{~h}$ will be adopted through the current investigations. Finally, the fabrication scheme, of aluminum/steel functionally graded materials, that used in the current investtigations can be schematically summarized as shown in Figure 3.

\section{Results and Discussion}

Six cylindrical aluminum/steel FGM specimens were fabricated with $21 \mathrm{~mm}$ diameter and $28 \mathrm{~mm}$ approximately height. Specimens for microstructural inspection were sliced with a diamond saw perpendicular to layer surface, and their surfaces were ground, polished carefully and examined using standard metallographic techniques. Macroand Microstructural features were characterized by optical microscopy (OM) and scanning electron microscopy (SEM) with (EDS) analysis using (JEDL-JSM 5400 LV) microscope.

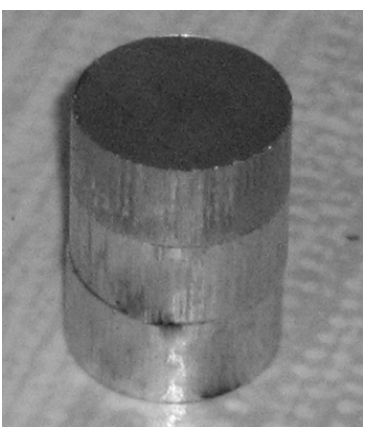

(a)

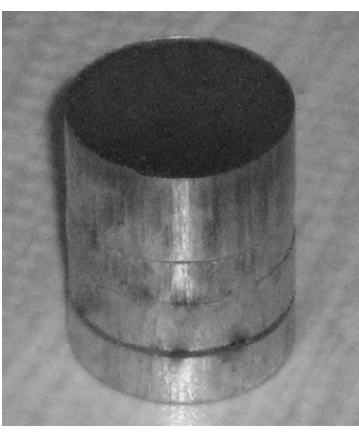

(b)
Figure 2. Compacted specimens with separating surfaces.

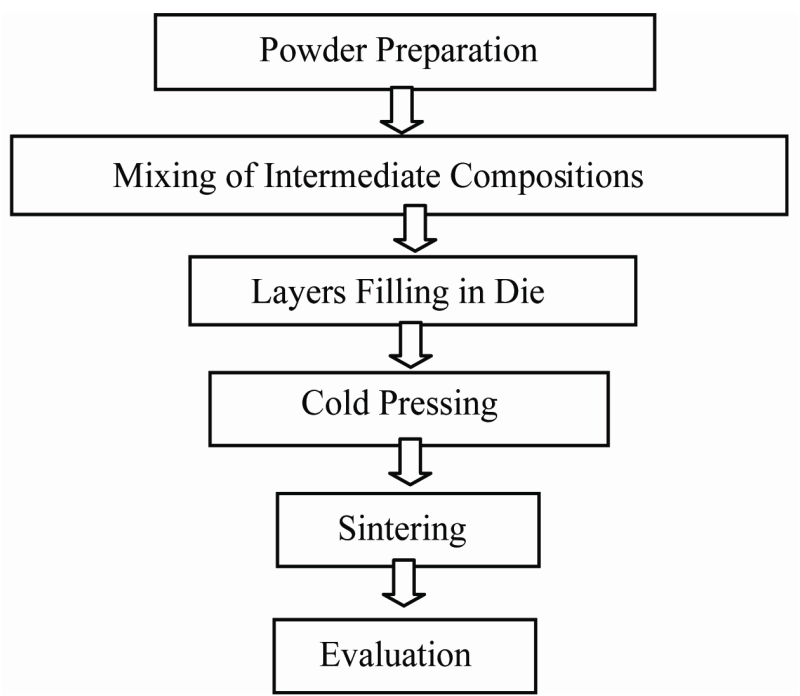

Figure 3. Flow chart of PM fabrication of functionally graded material. 
Figure 4 shows a general view and details of (SEM) with (EDS) analysis, where the aluminum phase appears dark and steel phase appears light.

Figure 5 shows the microstructures of the two layers specimen, $S_{1}$. Figure 5(a) shows the microstructure in the layer that has a composition of $100 \%$ steel and Figure 5(c) shows the microstructure in the layer that has a composition of 100\% aluminum while Figure 5(b) shows the microstructure at the interface between the $100 \%$ aluminum layer and $100 \%$ steel layer. One can see that a large only crack exist in the $100 \%$ aluminum. This crack is almost parallel to the interface between the steel and aluminum layers. The cause of the appearance of such crack is the high tensile thermal stresses that generated during cooling process, from sintering temperature to room temperature, due to the high difference between the coefficients of thermal expansion of steel and aluminum. The low mechanical strength of the aluminum leads to crack initiation and propagation in aluminum layer not in steel layer. Figure 6 shows SEM micrographs for the same specimen, $\mathrm{S}_{1}$, at two different magnifications, $\times 15$ and $\times 200$.

From Figure 6(a) it can be observed that two long cracks in aluminum phase and a sharp interface between the two layers are clearly appears. Also, Figure 6(b). shows SEM micrographs at $\times 200$ for crack in aluminum layer. White zone around crack is aluminum oxide. Finally, the appearance of cracks in two layers specimen is evident on the effectiveness of using FGM in the design of electric transition joint.

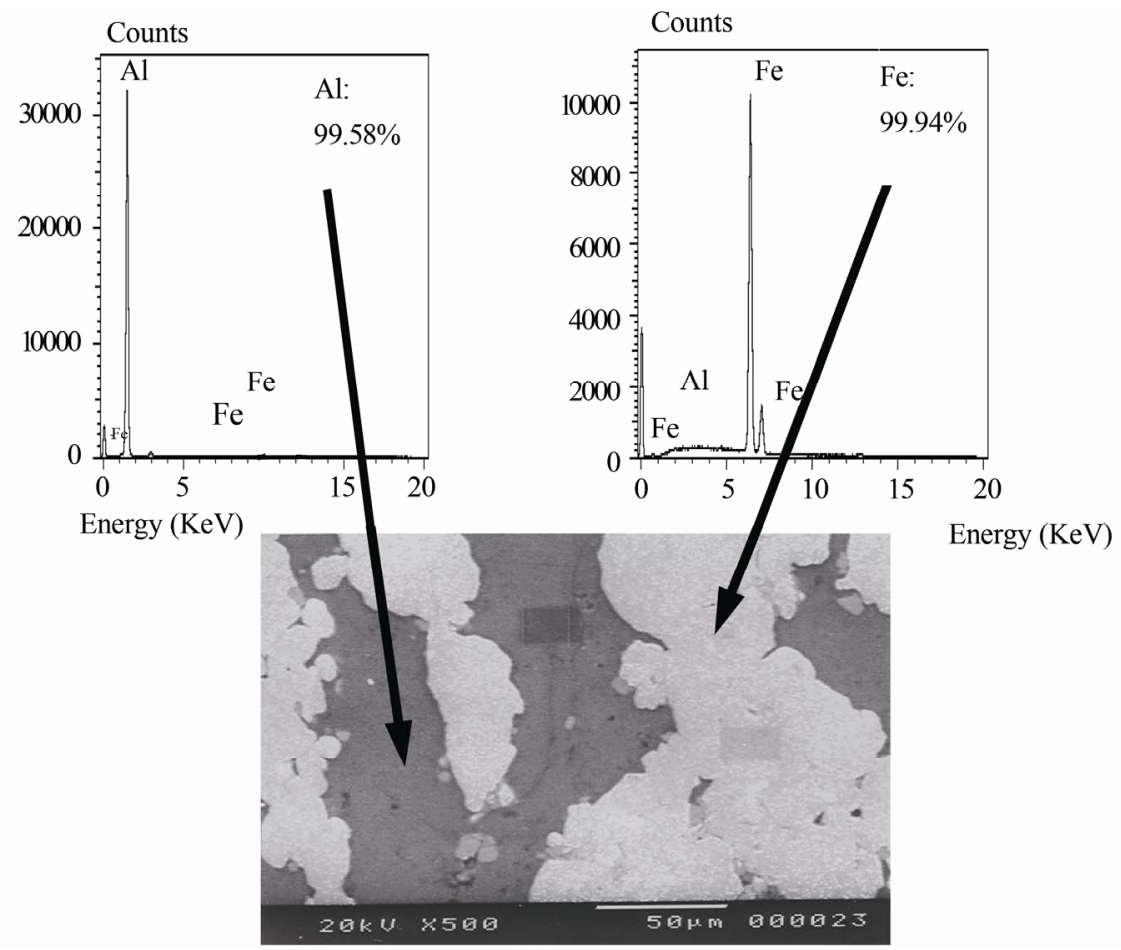

Figure 4. General details of aluminum/steel composite layer using scanning electron microscopy (SEM) at magnification of $\times 500$ and EDS analysis.

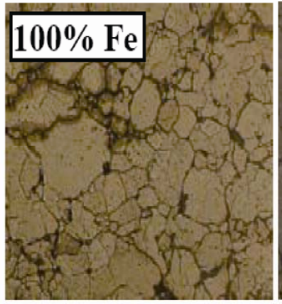

(a)

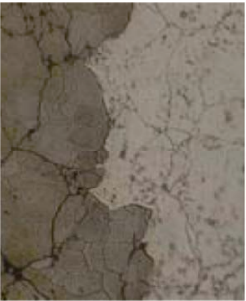

(b)

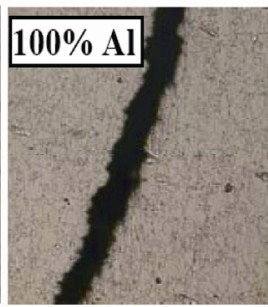

(c)

Figure 5. Optical micrographs at magnification of $\times 200$ for the two layers specimen, $S_{1}$.

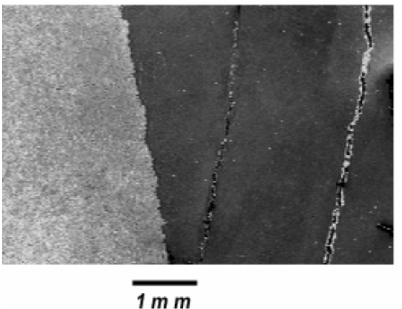

(a)

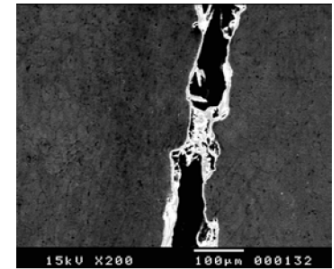

(b)
Figure 6. SEM micrographs at different magnifications (a) $\times 15$ and (b) $\times 200$. 
Figure 7(a) shows the macrophotograph of microstructure for the steel/aluminum graded three layers. It is interesting to note that crack-free steel/aluminum graded three layers specimen was successfully fabricated. The sharp interface composition was replaced with intermediate composition layer, where the microstructure and properties are smoothly varied from steel to aluminum through the height of the specimen. The weight percent variation of steel along the height of the specimen is shown in Figure 7(b), from 100 wt $\%$ of steel on the left side to $100 \mathrm{wt} \%$ aluminum on the right side.

SEM micrographs of steel/aluminum graded three layers, for specimen $S_{2}$, and X-ray energy dispersive spectrum (EDS) analysis are shown in Figure 8. It is clear that good agreement between EDS analysis and the composition of each layer which gives confidence in the obtained results.

Figure 9 shows the optical microstructures of the three

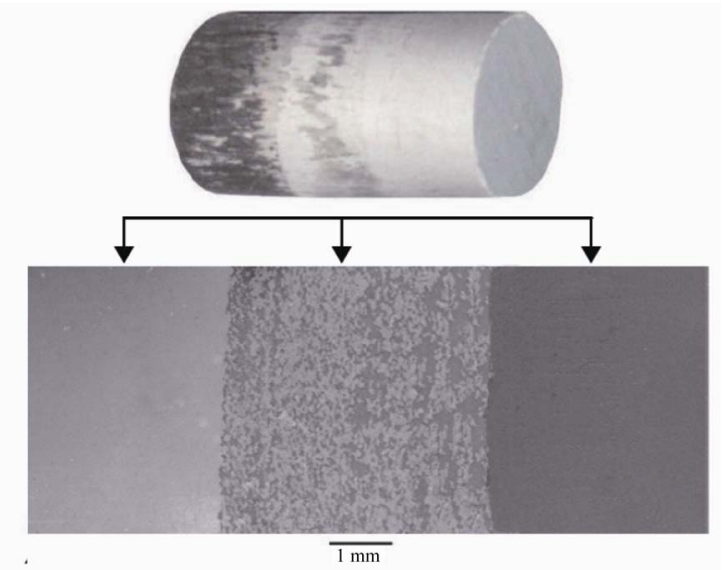

(a)

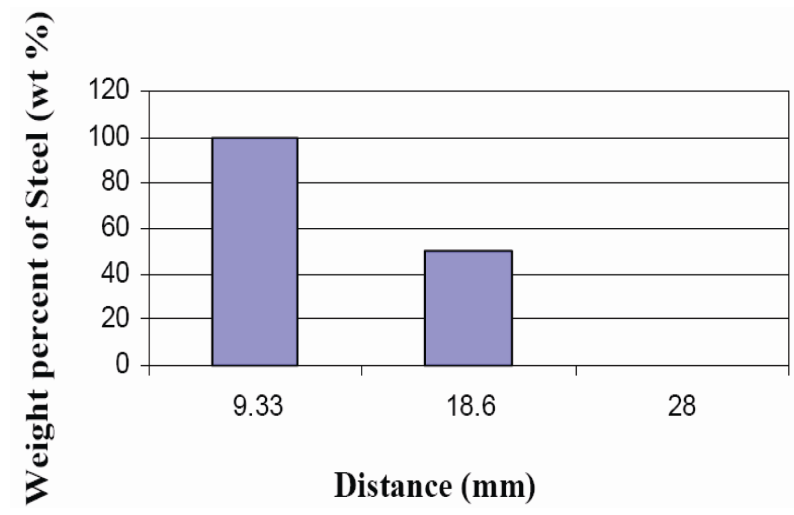

(b)

Figure 7. (a) Macrophotograph of microstructures for steel/ aluminum graded three layers, $\mathrm{S}_{2}$; (b) The variation of steel weight percent along the height of steel/aluminum graded three layers from the lower surface layer, that has $100 \mathrm{wt} \%$ steel.
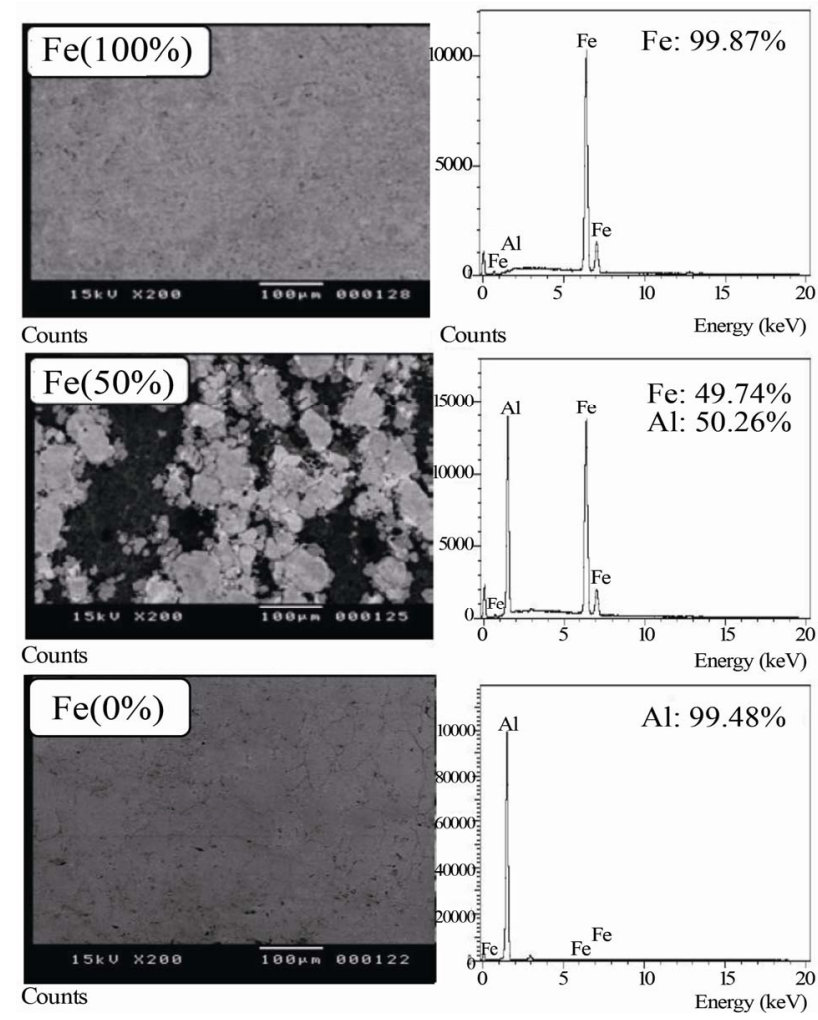

Figure 8. SEM micrographs at magnification of $\times 200$ and EDS analysis for steel/aluminum FGM specimen, $S_{2}$, that show the variation of the compositions through the layers.

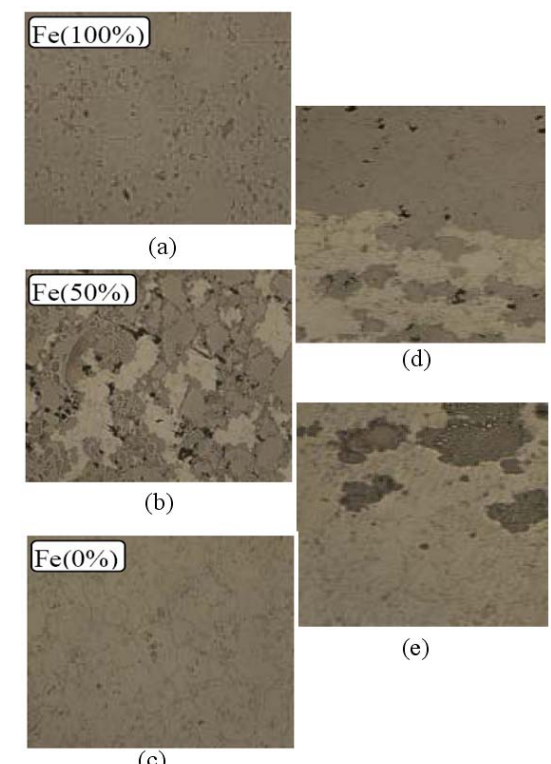

Figure 9. The optical microstructures of 3 layers graded specimen, $S_{2}$. (a) $100 \mathrm{w} \%$ steel layer; (b) $50 \mathrm{w} \%$ steel layer; (c) $100 \mathrm{w} \%$ aluminum layer; (d) The interface between 100 w\% steel layer and $50 \mathrm{w} \%$ steel layer; (e) The interface between $100 \mathrm{w} \%$ aluminum layer and $50 \mathrm{w} \%$ steel layer. 
layers aluminum/steel graded specimen, $\mathrm{S}_{2}$. Where Figure 9(a) shows $100 \mathrm{~W} \%$ steel layer, Figure 9(b) shows $50 \mathrm{~W} \%$ steel layer, Figure 9(c) shows $100 \mathrm{~W} \%$ aluminum layer, Figure 9(d) shows the interface between 100 W\% steel layer and $50 \mathrm{~W} \%$ steel layer and Figure 9(e) shows the interface between $100 \mathrm{~W} \%$ aluminum layer and $50 \mathrm{~W} \%$ steel layer. Generally from Figure 9 it is clear that gradual change of the layers composition or at the layers interface is quietly achieved.

Figure 10 shows the macrophotograph of microstructure for steel/aluminum 6 graded layers specimen, $S_{3}$. It is clear that both aluminum and steel components are continuous graded through the microstructure, this good continuity of microstructure can eliminate cracks that appear at the interface and reflects the design idea from using functionally graded materials.

Figure 11 shows macrophotograph of microstructure for steel/aluminum 6 graded layers specimen, $S_{3}$, and the corresponding steel weight percent of each layer from the height of the lower surface according to EDS analysis. Figure 12 shows optical micrographs at magnification of

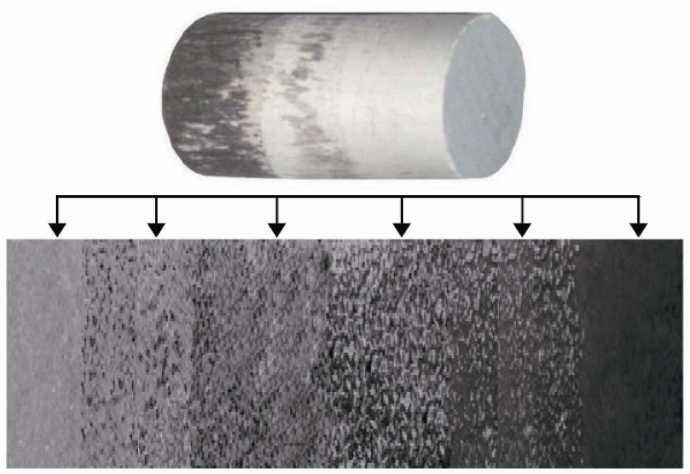

$\overline{1 \mathrm{~m} m}$

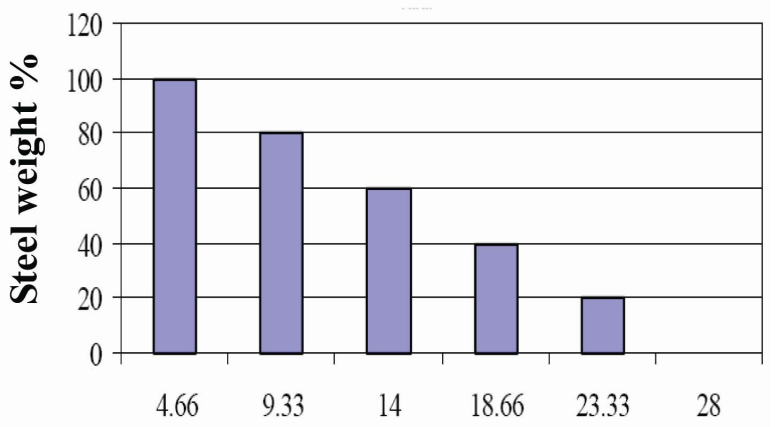

Distance in $\mathbf{m m}$

Figure 10. Macrophotograph of of micro structure for steel/ aluminum 6 graded layers specimen, $S_{3}$, and the corresponding steel weight percent of each layer from the height of the lower surface according to EDS analysis.
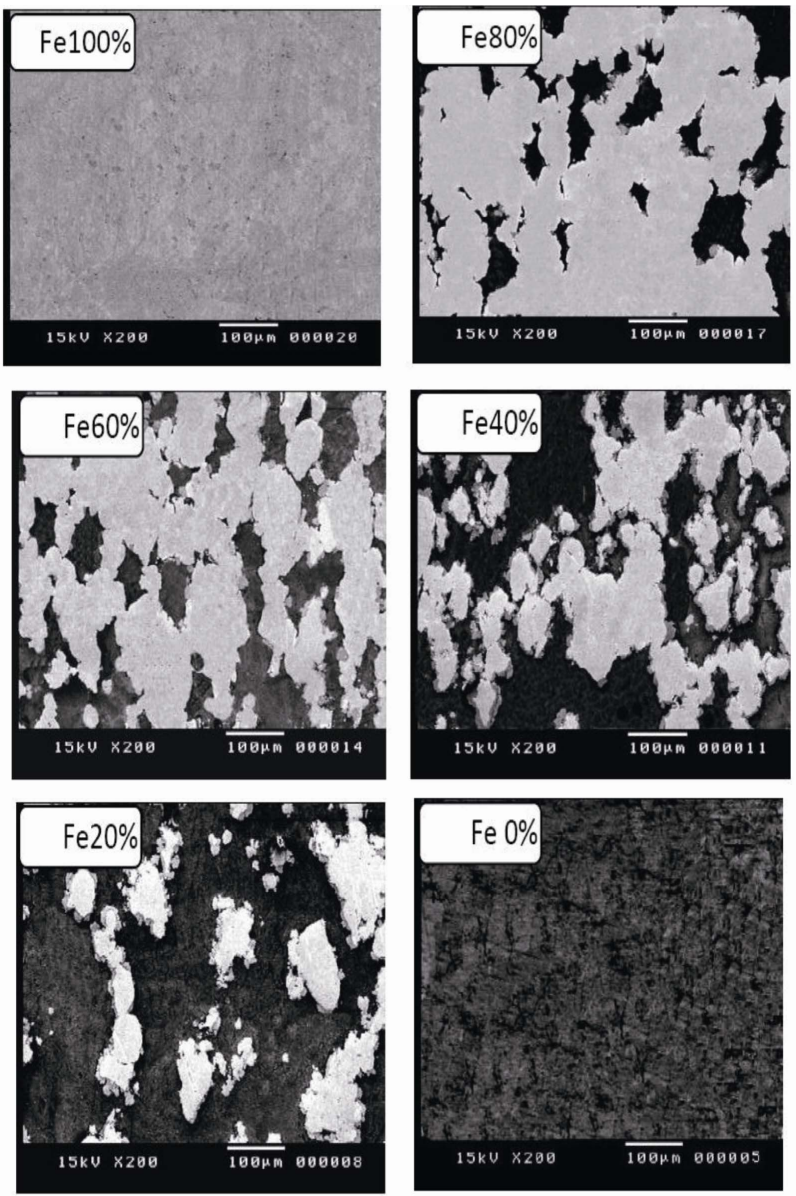

Figure 11. SEM micrographs at magnification of $\times 200$ for steel/aluminum 6 graded layers specimen, $S_{3}$.

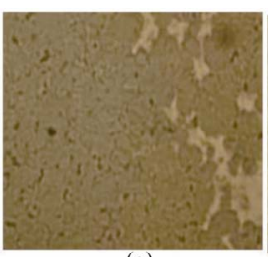

(a)

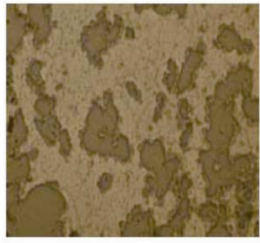

(d)

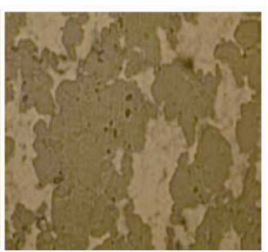

(b)

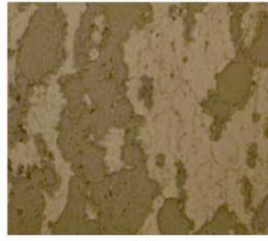

(c)

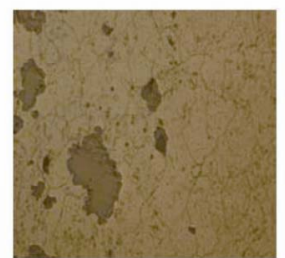

(e)

Figure 12. Optical micrographs at magnification of $\times 200$ at the interfaces of 6 graded layers specimen, $S_{3}$. (a) Interface between $1^{\text {st }}$ layer, $100 \mathrm{w} \%$ steel and $2^{\text {nd }}$ layer; (b) Interface between $2^{\text {nd }}$ layer and $3^{\text {rd }}$ layer; (c) Interface between $3^{\text {rd }}$ layer and $4^{\text {th }}$ layer; (d) Interface between $4^{\text {th }}$ layer and $5^{\text {th }}$ layer; (e) Interface between $5^{\text {th }}$ layer and $6^{\text {th }}$ layer. 
$\times 200$ at the interfaces of 6 graded layers specimen, $S_{3}$. It is worth to note that the optical micrographs at magnifycation of $\times 200$ for the different layers of 6 graded layers specimen, $\mathrm{S}_{3}$, are obtained but not shown. From Figures 10-12 it is very interesting to note that increasing the number of layers in specimen increased the interlock between steel and aluminum. Also, it can be seen that there are no defects observed, and smooth gradient distribution from steel to aluminum is successfully obtained

Figure 13 shows macrophotograph of microstructures of steel/aluminum 9 graded layers specimen and the corresponding steel weight percent along the height from the lower surface, $100 \%$ steel. It is clear that as the number of layers increases the difference of the composition between layers decreases. Figure 14 shows SEM micrographs at magnification of $\times 200$ for steel/aluminum 9 graded layers specimen, $\mathrm{S}_{4}$. Also, from Figure 14 it can be seen that very good gradual change of the basic constituents, steel and aluminum, through the layers from $100 \%$ steel to $100 \%$ aluminum.

Figure 15 shows Macrophotograph of microstructures for steel/aluminum 15 graded layers specimen and the corresponding steel weight percent according to EDS analysis along the height, from the lower surface, 100\% steel.

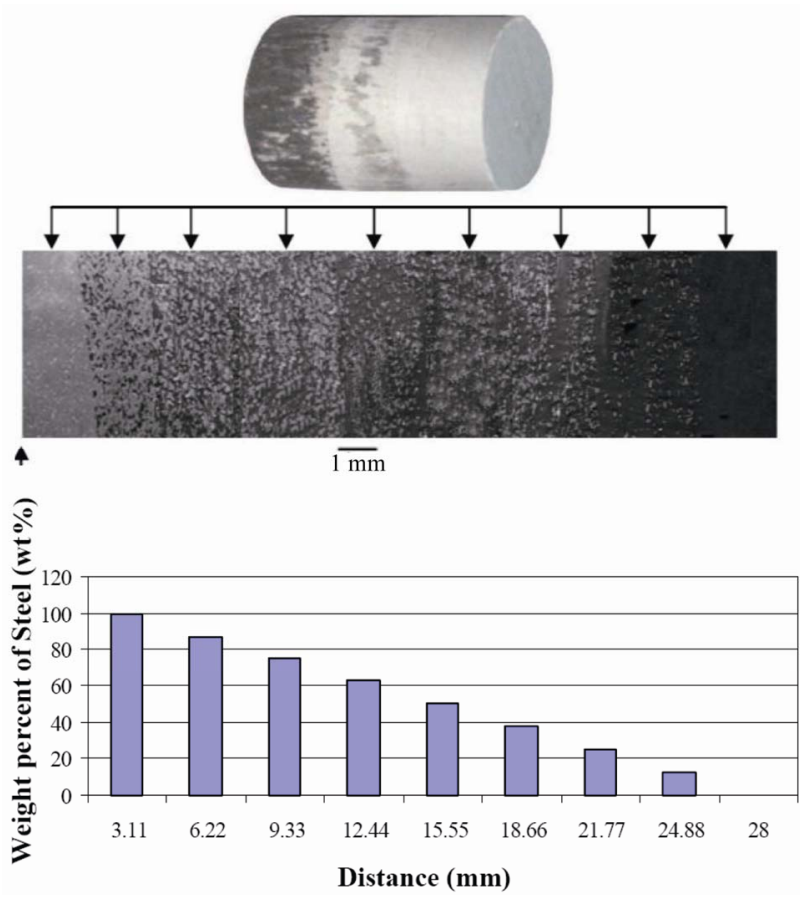

Figure 13. Macrophotograph of microstructures of steel/ aluminum 9 graded layers specimen and the corresponding steel weight percent according to EDS analysis along the height from the lower surface, $100 \%$ steel.
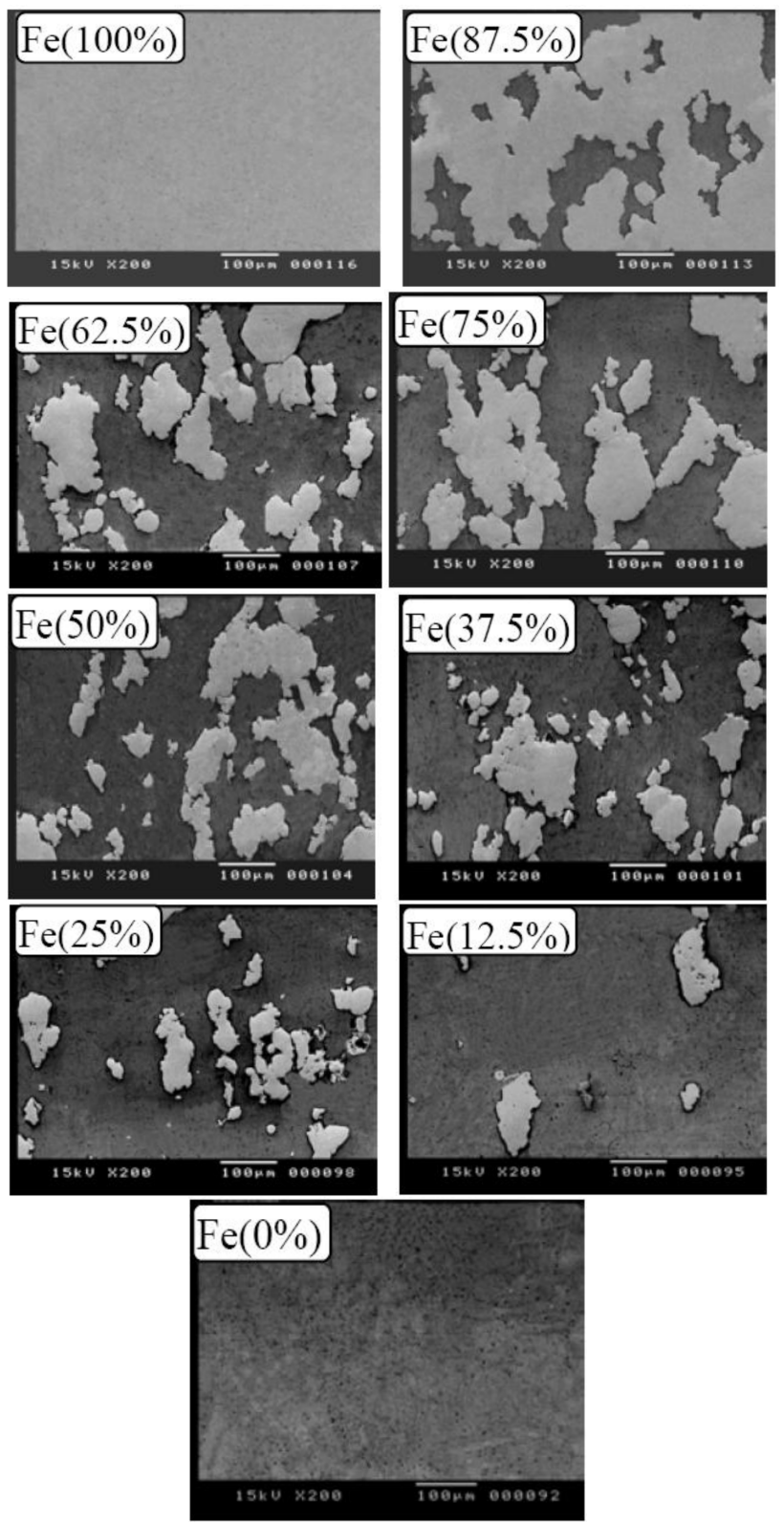

Figure 14. SEM micrographs at magnification of $\times 200$ for steel/aluminum 9 graded layers specimen, $\mathrm{S}_{4}$.

Also, SEM micrographs at magnification of $\times 200$ for steel/aluminum 15 graded layers specimen, $S_{5}$ was obtained, not shown here. From the above result, it is clear that increasing number of layers will reduce the interface between layers and produce functionally graded material not functionally graded layers. Therefore, steel/aluminum 21 graded layers will be adopted as steel/aluminum functionally graded material.

Figure 16 shows macrophotograph of microstructures for steel/aluminum graded material specimen, $S_{6}$, and the corresponding steel weight percent according to EDS 


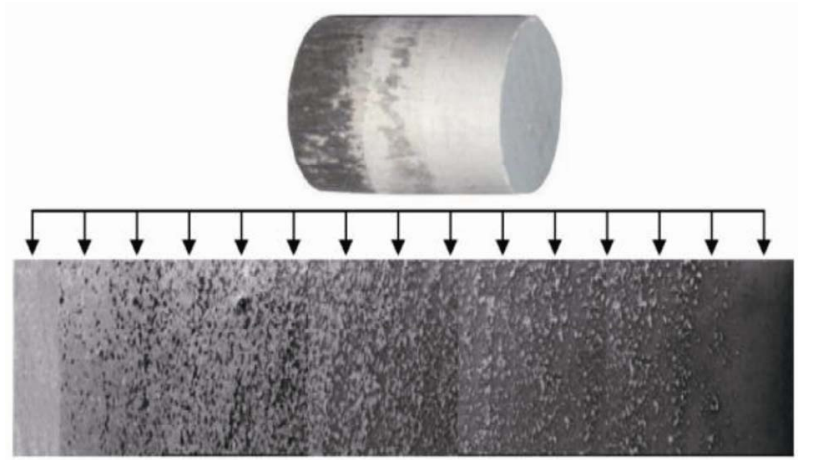

$1 \overline{\mathrm{mm}}$

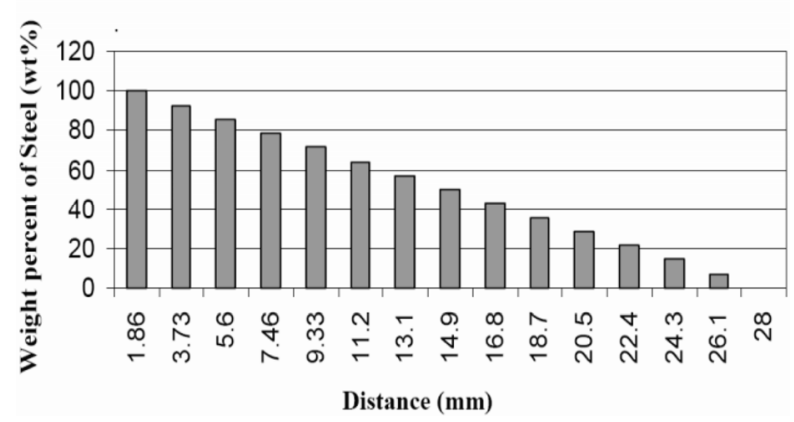

Figure 15. Macrophotograph of microstructures for steel/ aluminum 15 graded layers specimen and the corresponding steel weight percent along the height, from the lower surface, $100 \%$ steel.
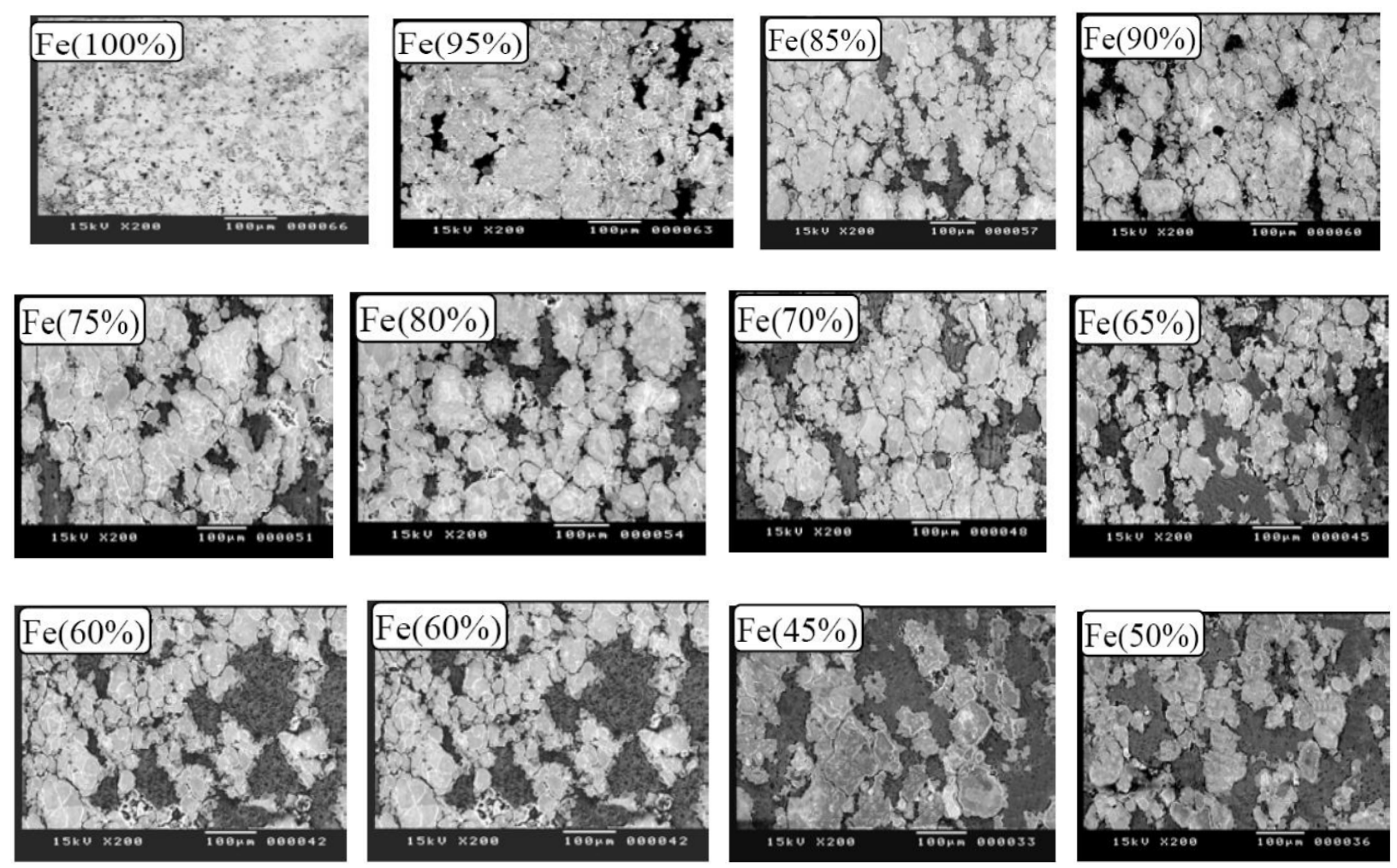

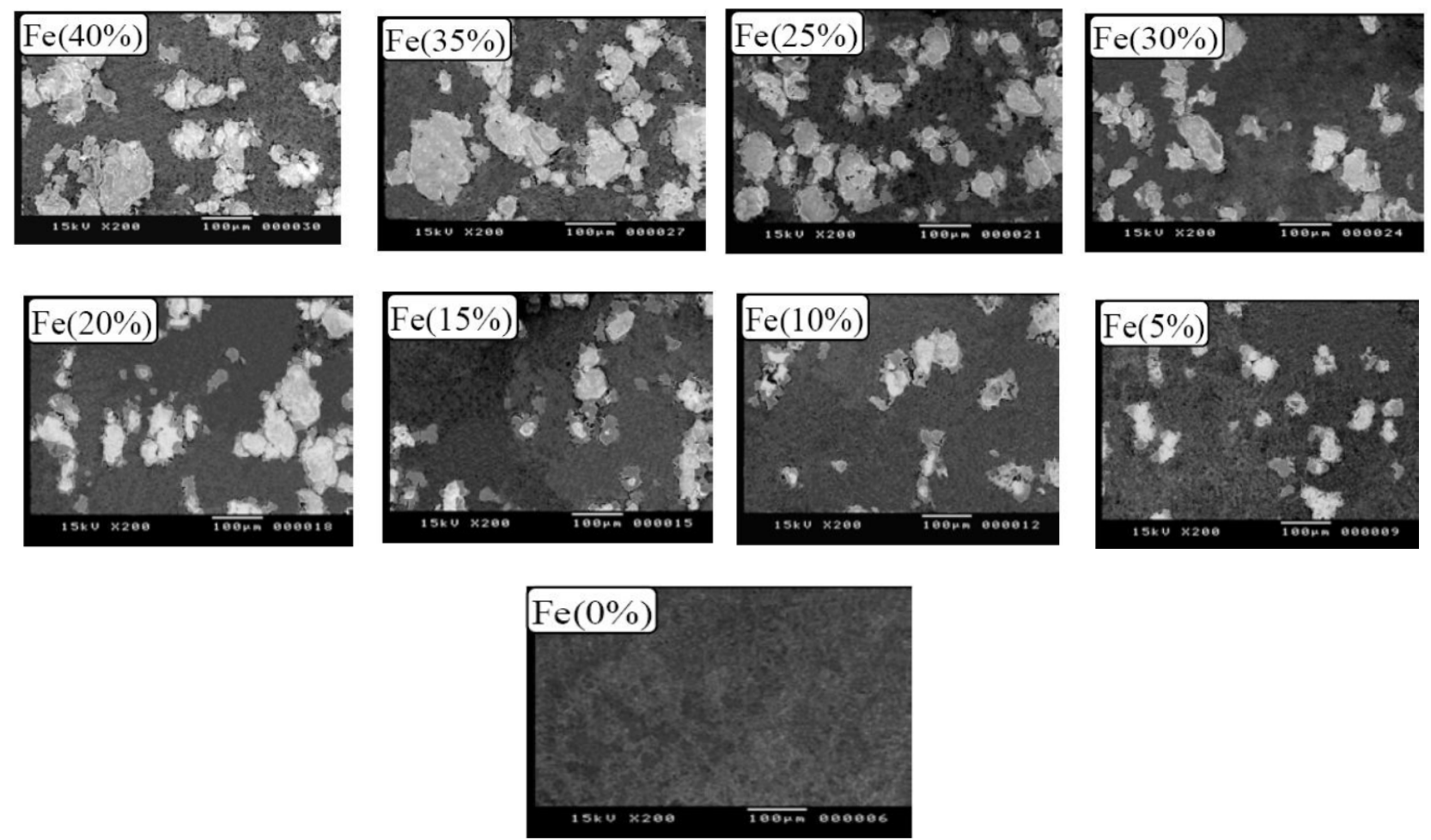

Figure 17. SEM micrographs at magnification of $\times 200$ for steel/aluminum functionally graded specimen.

analysis along the specimen height from the lower surface, 100\%. Figure 17 Shows SEM micrographs at magnification of $\times 200$ for steel/aluminum functionally graded specimen, $\mathrm{S}_{6}$. From Figures $\mathbf{1 6}$ and $\mathbf{1 7}$ it is clear that gradual variation of the basic components was achieved and steel/aluminum graded material specimen fabrication process was successful. The fabricated steel/aluminum graded material specimen with very smooth transition will leads to disappearing of the thermal stresses singularities and minimizing the stress concentration values.

\section{Conclusions}

1) A functionally graded steel/aluminum material was successfully fabricated by PM processing with com- position changing from $100 \%$ steel in one side to $100 \%$ aluminum in the other side.

2) The fabrication process of FGM by stacked layer by layer and finally compact them together without precompacting pressure is the successful way in the considered fabrication process.

3) For fabricated steel/aluminum FGM by PM, the sintering temperature should not increase above $600^{\circ} \mathrm{C}$ where a new compound was formed when sintering temperature above $600^{\circ} \mathrm{C}$.

4) Increasing the number of layers in steel/aluminum FGM can decrease the sharp interface between the layers and produce FGM instead of functionally graded layers material.

5) Smooth gradual change of the composition in the steel/aluminum FGM can eliminate the microscopic interface such as result as that traditional steel-alu- minum joint.

\section{REFERENCES}

[1] J. Banker and A. Nobili, “Aluminum-Steel Electric Transition Joints, Effects of Temperature and Time upon Mechanical Properties,” In: W. Schneider, Ed., Light Metals 2002, The Minerals, Metals, \& Materials Society, 2002, pp. 439-445.

[2] J. W. Elmer and D. D. Kautz, "Fundamentals of Friction Welding,” ASM Handbook, Welding, Brazing, \& Soldering, Vol. 6, 1993, pp. 150-155.

[3] T. Stotler, "Procedure Development and Practice Considerations for Inertia and Direct-Drive Friction Welding," ASM Handbook, Welding, Brazing \& Soldering, Vol. 6, 1993, pp. 888-891.

[4] A. Patterson, "Fundamentals of Explosion Welding," ASM Handbook, Welding, Brazing \& Soldering, Vol. 6, 1993, pp. 160-164.

[5] J. G. Banker and E. G. Reineke, "Explosion Welding," ASM Handbook, Welding, Brazing \& Soldering, Vol. 6, 1993, pp. 303-305.

[6] L. M. Smith and M. Celant, "Practical Handbook of 
Cladding Technology,” CASTI Publishing, Inc., Edmonton, 1998.

[7] D. L. Olson, T. A. Siewert, S. Liu and G. R. Edwards, "Roll Welding," ASM Handbook, Welding, Brazing \& Soldering, Vol. 6, 1993, pp. 312-314.

[8] N. Noda, S. Nakai and T. Tsuji, “Thermal Stresses in Functionally Graded Material of Particle-Reinforce Composite," Japanese Society of Mechanical Engineering Series A, Vol. 41, 1998, pp. 178-184.

[9] O. Bleek, D. Munz, W. Schaller and Y. Yang, "Effect of a Graded Interlayer on the Stress Intensity Factor of Cracks in a Joint under Thermal Loading," Engineering Fracture Mechanics, Vol. 60, No. 5-6, 1998, pp. 615-623. doi:10.1016/S0013-7944(98)00044-7

[10] M. Nemat-Alla, "Reduction of Thermal Stresses by Developing Two Dimensional Functionally Graded Materials," International Journal of Solids and Structures, Vol. 40, 2003, pp. 7339-7356. doi:10.1016/j.ijsolstr.2003.08.017

[11] M. Nemat-Alla, "Reduction of Thermal Stresses by Composition Optimization of Two-Dimensional Functionally Graded Materials,” Acta Mechanica, Vol. 208, No. 3, 2009, pp. 147-161. doi:10.1007/s00707-008-0136-1

[12] M. Nemat-Alla, K. Ahmed and I. Hassab-Allah, "Elastic-Plastic Analysis of Two Dimensional Functionally Graded Materials under Thermal Loading,” International
Journal of Solids and Structures, Vol. 46, No. 15-16, 2009, pp. 2774-2786. doi:10.1016/j.ijsolstr.2009.03.008

[13] D. Alton and J. Michael, "Combustion Synthesis of Advanced Materials," ASM Handbook, Powder Metal Technologies and Applications, Vol. 7, 1998, p. 1252.

[14] B. Kieback, A. Neubrand and H. Riedel, "Processing Techniques for Functionally Graded Materials,” Materials Science and Engineering A, Vol. 362, No. 1-2, 2003, pp. 81-106. doi:10.1016/S0921-5093(03)00578-1

[15] R. Watanabe and A. Kawaski, "Powder Metallurgical Fabrication of the Thermal Stress Relief Type of Functionally Gradient Materials,” Sintering, Elsevier, Tokyo, Vol. 2, 1987, pp. 1197-1202.

[16] T. Schubert, T. Weibgarber, B. Kieback, H. Balzer, H. C. Neubing, U. Baum and R. Braum, "Aluminum PM is a Challenge That Industry Can Overcome,” Metal Powder Report, Vol. 60, No. 3, 2005, pp. 32-37. doi:10.1016/S0026-0657(05)00370-X

[17] K. Y. Sastry, L. Froyen, J. Vleugels, O. Van der Biest, R. Schattevoy and K. Hummert, "Field Assisted Sintering Consolidation of Al-Si-Fe-X Alloy Powder/Flakes Produced through Air Atomization/Melt Spinning,” Material Science Forum, Vol. 519-521, 2006, pp. 1409-1414. doi:10.4028/www.scientific.net/MSF.519-521.1409

[18] P. C. Sharma, "Production Engineering," S. Chand \& Company Ltd., New Delhi, 1993, pp. 894-8896 